\title{
The voices of children and young people in health: where are we now?
}

\author{
Leonora G Weil, ${ }_{1}^{1}$ Claire Lemer, ${ }^{2}$ Elspeth Webb, ${ }^{3}$ Dougal $S$ Hargreaves ${ }^{4}$
}

\begin{abstract}
'Make decisions about us, with us. Let us have our say!'

Royal College of Paediatrics \& Child Health Youth Advisory Panel member ${ }^{1}$
\end{abstract}

Universal children's day on 20 November 2014 marked the 25th anniversary of the UN Convention on the Rights of the Child (UNCRC, 1989) ${ }^{2}$ and the 55th anniversary of the Declaration of the Rights of the Child (1959). ${ }^{3}$ Twenty-five years after the UNCRC, this article explores the rights of children and young people (CYP) to participate in decisions about their healthcare, and the benefits of doing so; we then examine where we are now with respect to the voices of CYP in health. This article addresses this final question through three aspects: first, by celebrating the progress made over the last quarter of a century-particularly with respect to policy development-both in the UK and internationally; second, by identifying ongoing areas of concern, with suggestions as to where to focus our efforts next; and finally, by calling for a change in culture. This change of culture is suggested through four positive concrete steps: a greater dissemination of guidance and examples of good practice, greater evaluation of the participatory process, appropriate training and procedures in place to support CYP participation and finally encouraging increased involvement of CYP in improving their own health. Through these steps, we aim towards a culture where CYP are valued, heard, understood and, ultimately, their rights are respected.

\section{THE RIGHTS OF CYP AND PARTICIPATION}

With the UNCRC having been ratified by most UN member countries (the UK in 1991), such landmark agreements focus attention on the fundamental and

\footnotetext{
${ }^{1}$ Public Health Registrar, London, UK; ${ }^{2}$ Department of General Paediatrics, Evelina London Children's Hospital, London, UK; ${ }^{3}$ Institute of Molecular and Experimental Medicine, School of Medicine, Cardiff University, Cardiff, UK; ${ }^{4}$ Department of Population, Policy \& Practice Programme, UCL Institute of Child Health, London, UK

Correspondence to Dr Dougal S Hargreaves, Population, Policy \& Practice Programme, UCL Institute of Child Health, 30 Guilford Street, London WC1N 1EH, UK; d.hargreaves@ucl.ac.uk
}

inalienable rights applicable to every child and young person worldwide. An important element of these rights is the right to participate in decisions about their own care, including their healthcare. Support for the participatory role of CYP includes the right to express their views in all matters that affect them, 'the views of the child being given due weight in accordance with the age and maturity of the child' (Article 12); 'the right to freedom of expression' (Article 13); 'freedom of thought' (Article 14); 'the right to freedom of association' (Article 15) and 'the right to information' (Articles 13 and 17). Particularly applicable to the right of CYP to participate in decisions about their health is Article 24, Section 2 (e), which is 'to ensure that all segments of society, in particular parents and children, are informed, have access to education and are supported in the use of basic knowledge of child health and nutrition, the advantages of breast feeding, hygiene and environmental sanitation and the prevention of accidents'.

Evidence shows that CYP highly value their participatory involvement in healthcare, ${ }^{45}$ that they see this as an important priority $^{67}$ and that there are benefits to both services and users in consulting CYP. ${ }^{8-11}$ While different degrees of participation may be relevant in different circumstances, ${ }^{12}$ if participation is 'a process where someone influences decisions about their lives and this leads to change, ${ }^{4}$ it should be more than just a tokenistic exchange. Rather, participation should be essential in the endeavour to get CYP views into the system of health planning and policy. Twenty-five years after CYP were given the right to 'say what they think', are they any nearer that goal?

\section{THE VOICES OF CYP IN THE UNITED KINGDOM}

Any policy written about CYP should incorporate their opinions. Understanding their motivations is imperative in ensuring that policy recommendations are appropriate and that CYP are likely to understand and respond to them. Indeed, involving every patient in their own care has become a gold standard, as outlined in the NHS Constitution $^{13}$ and in the 2010 White Paper, 'Equity and Excellence: Liberating the NHS' ${ }^{14}$ The White Paper was based on the principle of 'no decision about me, without me' and emphasised that 'involving patients in their care and treatment improves their health outcomes, boosts their satisfaction with services received, and increases not just their knowledge and understanding of their health status but also their adherence to a chosen treatment'. This applies just as much to CYP as any other patient group. ${ }^{15}$

The 2012 annual report of the Chief Medical Officer of England, 'Our children deserve better: prevention pays', ', highlighted the prominence of CYP as central to health policy in the NHS and celebrated their growing 'participatory role' in the English health system over recent years (box 1). The report presented a CYP manifesto for health and well-being. Building on this manifesto, one important recommendation was the development of a new 'health deal'-a vision for engaging CYP in their health and health services.

There have also been a number of recent developments in Scotland, Northern Ireland and Wales. For example, in Scotland 10 years ago, the West Lothian Children's Rights Forum was established to 'give looked after CYP a voice and a structure to influence decision makers' ${ }^{16}$ In Northern Ireland, the CYP's Strategic Partnership (CYPSP) was founded in 2011 to bring together a range of agencies to improve the lives of CYP. As an extension of this, a strategy was developed to ensure a participatory role of CYP in the CYPSP with the aim that 'CYP will be active participants in the planning of services and that their experiences, views and ideas help inform the planning process'. ${ }^{17}$ In Wales, almost a decade ago, the Welsh National Service Framework (NSF) recommended that agencies develop a timetabled plan for implementing a policy for the participation and partnership of CYP and their families in both planning and evaluating services affecting them.

\section{THE GLOBAL CONTEXT}

Beyond the UK, there are many lessons to be learned about how voices of CYP are changing the way that decisions are made and services are delivered across all five WHO regions. ${ }^{18}$ One important example in high-income countries is the 2011 Guidelines for Child Friendly Healthcare, which were endorsed by 47 members of the Council of Europe, following extensive consultation with over 2000 CYP in 22 countries. ${ }^{19}$ These guidelines are explicitly based on CYP rights within the UNCRC, as well as their wider views and priorities. Parallel work in other countries 
Box 1 The growing participatory role of young people in the English Health system.

- The National Service Framework for Children, Young People and Maternity Services (2004) recommended that 'children, young people and their parents participate in planning, evaluating and improving the quality of services'.

- The Children's Commissioner for England's post was established in the 2004 Children Act to 'represent the views and interests' and in the Children and Families Act 2014 was strengthened to 'promote and protect children's rights in accordance with the United Nations Convention on the Rights of the Child'. Children and young people (CYP) themselves are involved in appointing the Children's Commissioner.

- In 2011, through the 'You're Welcome' quality criteria, endorsed by the WHO, England, was the first country to publish universal quality standards for adolescent care that aim to ensure all young people have their say about the health services they use.

- In March 2014, a strategic voice for CYP was formalised through the launch of the NHS Youth Forum.

- In 2015, CYP were included for the first time in the Friends and Family test, which provides opportunity for patient feedback, and inspections by the Care Quality Commission will have a greater focus on the voice of CYP and families who use the service.

includes the Youth Friendly Hospital Programme in Australia and the Give Youth a Voice questionnaire developed in Canada.

The right for CYP to be heard was a key strand of the WHO's early work to improve services for adolescents in lowincome and middle-income countries, summarised in Adolescent Friendly Services: An Agenda for Change, 2002. ${ }^{20}$ This report highlighted widespread shortcomings in the ability of health services to meet the needs of adolescents, and advocated for the development of adolescent-friendly services. To illustrate this approach, the WHO reported many innovative projects serving diverse populations-from street children in the Philippines to adolescents in remote rural communities in Mexico. Violence and social inequalities were major themes in the Americas, nutrition and mental health needs in India and sexual health/HIV a common focus in many areas, including Africa and Eastern Europe.

The global evidence base for CYP participation in health is also growing rapidly, with the recent publication of a systematic review of young people's perspectives on healthcare quality and three validated measures of young-personfriendly care. $^{6}{ }^{21-23}$ This work covered: development and validation of a new survey of primary care for young people in Bosnia and Herzegovina; quality standards developed in partnership with professionals and young people at a wide range of community and hospital services in England; and a framework for defining and measuring quality of inpatient care developed in partnership with young researchers in Australia. These projects demonstrate how common participation themes may be applied in different ways depending on the context. Recent work in many countries also reinforces how the research and policy in this field has broadened over the last decade from a focus on adolescents (10-19 years) to include the voice of younger children and young adults, ranging from preschool children to young people aged up to 25 years.

\section{WHERE NEXT?}

As the UNCRC enters its 25th year, we can see that there is much to celebrate; a great deal has been achieved in the UK and worldwide to ensure that CYP's views are represented in health.

There is, however, still much work to be done. Since the UNCRC was ratified, there has been no shortage of guidance about how to ensure a participatory role of CYP in healthcare; ${ }^{8} 12$ yet, according to the Children's Commissioner for England's 2013 report: 'children's participation has not been sufficiently embedded into everyday practice and largely relies on the commitment of key individuals. ${ }^{5}$ This report highlighted that, of 102 local health plans, only $28 \%$ actively involved CYP. A recent report prepared by the Patient Experience Network for NHS England found that less than half of the respondents had a specific CYP strategy, that most survey and development work were centred on adults' views, with comparatively greater weight given to the adults' viewpoint. ${ }^{24}$ It is not only in England where participation of CYP is 'not sufficiently embedded' despite previous progress; in Wales, CYP panels were proposed for every hospital as part of the Welsh NSF recommendations, but few have come to fruition, ${ }^{25}$ and from
September 2014, the Welsh Children's Assembly had its core funding withdrawn by the Welsh Government. ${ }^{26}$

Although far from the whole solution, the extent to which CYP rights are met in the future may depend on a change in culture in four key areas.

First, there is a need for greater dissemination of the available guidance, with the aim of demystifying the process of participation and ensuring that it is done well. Many professionals are deterred by fears that CYP have insufficient understanding to participate meaningfully or that too many resources are required. ${ }^{11}$ Participation activities need not be expensive, and there are examples of good practice ranging from the formation of a hospital trust youth engagement team to a school competition to design the interior of a new local paediatric intensive care unit. ${ }^{24}$ For sustainable, highquality participation activity, it is also important to ensure the inclusion of the full range and diversity of voices among patients attending that service. Depending on the context, this may involve ensuring representation of CYP from all socio-demographic groups, a range of ages and those with a wide range of medical conditions. High-quality, practical guidance is available, which shows what is possible (even with very few resources), and can ensure that potential pitfalls are avoided. ${ }^{12} 27$

Second, there is a need for greater evaluation of how lessons learnt through the participatory process with CYP are acted on, and what long-term changes are made. ${ }^{12} 2829$ This stage in the process is often underdeveloped, and without this step, it is difficult to feed back into the process to ensure that CYP are listened to, and changes are made. According to Cavet and Sloper, 'the most glaring gap in the evidence is the lack of evaluation of work undertaken, especially as regards any impact on service development from the involvement of young people'. ${ }^{8}$ It is also important that CYP are involved in this evaluatory stage of the process.

Third, there must be appropriate training, structures and procedures in place to support individuals and organisations in CYP participation. According to a report exploring children's participation in decision-making developed with the National Children's Bureau and the Office of the Children's Commissioner: 'there remains a high demand for further training on evaluating children's participation and training on participation techniques and strategies. Senior staffs, however, are still less likely than front-line participation workers to receive training in participation. This would suggest that there is a bottom-up 
approach to training opportunities in participation'. ${ }^{10}$ If there is no provision of accessible CYP-friendly pathways into participation, if privacy is not prioritised, if some socio-demographic groups are not represented or if CYP perceive that they are not protected from the consequences of participation, including complaints, then meaningful participation is compromised. Enabling complaints by CYP for example, need a holistic rights-led approach, which incorporates provision, protection and participation for it to be effective.

Lastly, many CYP want to be more involved in managing and improving their own health, as well as in improving healthcare services. ${ }^{1}$ However, there is large variation in services' ability to meet these needs. For example, some trusts are developing specific websites or apps that are appropriate for CYP, empowering them to understand their illness and work in partnership with professionals to manage their treatment. However, in many other hospitals, internet access is not reliably available, and much fewer opportunities are available for CYP to become more involved in decisions about their care. ${ }^{30}$

We propose that sustained progress in the future will depend on participation becoming a routine part of the culture of healthcare at all levels-from the 'micro' level of individual consultations between CYP and professionals, the 'meso' level of quality improvement and service development and the 'macro' level of regional or national policy development. Echoing the findings of the Francis report, ${ }^{31}$ guidelines, policy initiatives and research findings are no substitute for building a culture where CYP are valued, their voices listened to, their needs understood and their rights respected. The work described in the box should not be interpreted as a set of discrete initiatives to be implemented over and above mainstream mechanisms of care delivery; rather, it should be seen as a core framework of a health service in which CYP rights are embedded and their voices heard as a matter of course.

Twenty-five years after the UNCRC, CYP still want their voice to be heard. All those working in health-whether at the micro, meso or macro level-must ensure that they are ready to listen, and to act on what they hear.

Acknowledgements The authors thank Dr Maggie Atkinson, former Children's Commissioner for England, for commenting on an earlier draft of this article.

Contributors DSH conceived the article. LGW led writing of the manuscript. All authors contributed to drafting and critically revising the manuscript.

Competing interests None declared.
Provenance and peer review Commissioned; externally peer reviewed.
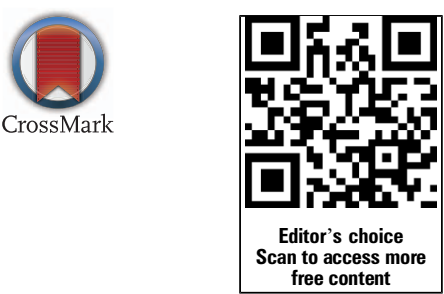

To cite Weil $L G$, Lemer $C$, Webb $E$, et al. Arch Dis Child 2015;100:915-917.

Received 10 October 2014

Revised 11 May 2015

Accepted 13 May 2015

Published Online First 4 June 2015

Arch Dis Child 2015;100:915-917.

doi:10.1136/archdischild-2014-307492

\section{REFERENCES}

1 Davies SC. Annual report of the chief medical officer 2012. Our Children Deserve Better: Prevention Pays. London: Department of Health, 2013. https://www.gov. uk/government/uploads/system/uploads/attachment_ data/file/255237/2901304_CMO_complete_low_res accessible.pdf (accessed 5 May 2015).

2 United Nations Office of the High Commissioner for Human Rights. Convention on the Rights of the Child. 1989. http://www.ohchr.org/EN/Professionallnterest/ Pages/CRC.aspx (accessed 5 May 2015).

3 United Nations General Assembly. Declaration of the Rights of the Child. 1959. http://www.un.org/ga/ search/view_doc.asp?symbol=A/RES/1386\%28XIV\% 29 (accessed 5 May 2015).

4 Burke T. Anyone listening? Evidence of children and young people's participation in England. London: Participation Works, 2010. http://www.crae.org.uk/media/ 26261/anyone_listening.pdf (accessed 5 May 2015).

5 Blades R, Renton Z, La Valle I, et al. We would like to make a change: children and young people's participation in strategic health decision-making. London: Office of the Children's Commissioner, 2013. http://ncb.org.uk/media/914734/we_would like_to_make_a_change_-_participation_in_health decisions_-_final2.pdf (accessed 5 May 2015).

6 Ambresin A-E, Bennett K, Patton GC, et al. Assessment of youth-friendly health care: a systematic review of indicators drawn from young people's perspectives. J Adolesc Health 2013;52:670-81.

7 Bensted R, Hargreaves DS, Lombard J, et al. Comparison of healthcare priorities in childhood and early/late adolescence: analysis of cross-sectional data from eight countries in the Council of Europe Child-friendly Healthcare Survey, 2011. Child Care Health Dev 2014;41:160-5.

8 Cavet J, Sloper P. The participation of children and young people in decisions about UK service development. Child Care Health Dev 2004;30:613-21.

9 Day C. Children's and young people's involvement and participation in mental health care. Child Adolesc Ment Health 2008;13:2-8.

10 Davey C. Children's participation in decision-making. A summary report on progress made up to 2010. London: Participation Works, 2010. http://www. participationworks.org.uk/files/webfm/files/npf /npf_ publications/A\%20Summary\%20Report_jun10.pdf (accessed 5 May 2015).

11 Bedford Russell AR, Passant M, Kitt H. Engaging children and parents in service design and delivery. Arch Dis Child 2014;99:1158-62.

12 Wood D, Turner G, Straw F. Not just a phase: a guide to the participation of children and young people in health services. London: RCPCH, 2010. http://www. rcpch.ac.uk/system/files/protected/page/RCPCH_Not Just_a_Phase_0.pdf (accessed 5 May 2015).
13 Department of Health. The NHS constitution for England. London: Department of Health, 2013.

14 Department of Health. Equity and excellence: liberating the NHS. London: Department of Health, 2010. https://www.gov.uk/government/uploads/ system/uploads/attachment_data/file/213823/dh_ 117794.pdf (accessed 5 May 2015).

15 Hargreaves DS. Learning to listen: delivering patient-centered care for adolescents. J Adolesc Health 2014;55:463-4.

16 Scottish Health Council. Case Study: West Lothian Children's Rights Forum. Having your Say 2013. http://www.scottishhealthcouncil.org/publications/ research/involvement_in_health_and_care.aspx\#. VUh0iBa0Lww (accessed 5 May 2015).

17 The Participation Network. Strategy for ensuring the participation of children and young people for the children and young people's strategic partnership. 2011. http://www.cypsp.org/wp-content/uploads/2015/01/ cypsp_participation_strategy.pdf (accessed 9 May 2015).

18 WHO. Department of Maternal, Newborn, Child and Adolescent Health. Making health services adolescent friendly: developing national quality standards for adolescent friendly health services. 2012. http://apps. who.int/iris/bitstream/10665/75217/1/ 9789241503594 eng.pdf (accessed 5 May 2015).

19 Council of Europe Committee of Ministers. Guidelines on child-friendly health care. Council of Europe 2011. https://wcd.coe.int/ViewDoc.jsp? $\mathrm{id}=1836421$ \& Site $=$ COE (accessed 5 May 2015).

20 WHO. Adolescent friendly health services: an agenda for change. Geneva: World Health Organization, 2002.

21 Haller DM, Meynard A, Pejic D, et al. YFHS-WHO+ questionnaire: validation of a measure of youthfriendly primary care services. J Adolesc Health 2012;51:422-30.

22 Hargreaves DS, McDonagh JE, Viner RM. Validation of You're Welcome quality criteria for adolescent health services using data from national inpatient surveys in England. J Adolesc Health 2013;52:50-7.

23 Sawyer SM, Ambresin A-E, Bennett KE, et al. A measurement framework for quality health care for adolescents in hospital. J Adolesc Health 2014;55:484-90.

24 The Patient Experience Network. Improving Patient Experience for Children and Young People. For NHS England 2013. http://patientexperiencenetwork.org/ wp-content/uploads/2013/11/PEN-Improving-PE-forChildren-Young-People-Report-FINAL-Electronic-file. pdf (accessed 5 May 2015).

25 Webb E. Health and health services. In: Croke R, ed. Right here, right now: are children's rights a reality in Wales? Cardiff: The Wales Programme of Save the Children, 2013:48-58. http://www.swansea.ac.uk/ media/FInal\%20Rights\%20here\%20right\%20now\% 20Report\%20E.pdf (accessed 5 May 2015).

26 Bird N. Funky Dragon youth assembly from Wales "facing closure". BBC News, 11 July 2014. http:// www.bbc.co.uk/news/uk-wales-28257420 (accessed 5 May 2015).

27 Robertson S, Pryde K, Evans K. Patient involvement in quality improvement: is it time we let children, young people and families take the lead? Arch Dis Child Educ Pract Ed 2014:99:23-7.

28 Franklin A, Sloper P. Listening and responding? Children's participation in health care within England. Int J Child Rights 2005;13:11-30.

29 Kirby P, Bryson S. Measuring the magic? Evaluating and researching public decision making. Nottingham: Carnegie Young People Initiative, 2002. http://www. participationworks.org.uk/files/webfm/files/resources/ k-items/carnegie/Measure\%20the\%20Magic.pdf (accessed 5 May 2015).

30 Rees T, Brooks R, Webb E. Internet access for inpatients. Arch Dis Child 2013:98:746-7.

31 Francis R. Report of the Mid.Staffordshire NHS Foundation Trust Public Inquiry. London: The Stationery Office, 2013. 